\title{
Influence of Nickel on the Oxidation Resistance at High Temperatures of Thin Chromium Coatings
}

\author{
Grzegorz Smola $^{1} \cdot$ Richard Gawel $^{1} \cdot$ Karol Kyziol $^{1} \cdot$ Maria MiszCzak $^{1}$. \\ Zbigniew Grzesik ${ }^{1}$ (D)
}

Received: 10 September 2018 / Revised: 14 January 2019 / Published online: 12 February 2019

(c) The Author(s) 2019

\begin{abstract}
The oxidation behavior of four valve steels (X33CrNiMn23-8, X50CrMnNiNbN21-9, X53CrMnNiN20-8 and X55CrMnNiN20-8) covered with thin sputterdeposited coatings containing chromium and nickel was studied under isothermal and thermal shock conditions. It was determined that coated steels exhibit greater resistance against oxidation than steels with unmodified surfaces. This effect results from the formation of chromium-rich oxides (e.g., $\mathrm{Cr}_{2} \mathrm{O}_{3}, \mathrm{NiCr}_{2} \mathrm{O}_{4}, \mathrm{MnCr}_{2} \mathrm{O}_{4}$ ) during oxidation of the surface modified steel. These oxides exhibited better protective properties than the products grown on unmodified steels (namely $\mathrm{Fe}_{3} \mathrm{O}_{4}$ and $\mathrm{Fe}_{2} \mathrm{O}_{3}$ ). The entirety of the obtained experimental results confirms the possibility of increasing the scaling resistance of valve steels by using around $1-\mu \mathrm{m}$-thick chromium-rich protective $\mathrm{Cr}-\mathrm{Ni}$ coatings.
\end{abstract}

Keywords Stainless steel · Chromium-based coatings - Thermal cycling $\cdot$ Hightemperature corrosion

\section{Introduction}

One of the most effective methods for protecting materials that work at high temperatures and in aggressive gas atmospheres is the application of protective coatings [1-4]. Among the most effective are so-called thermal barrier coatings (TBC), which combine excellent protective properties against both high temperatures and aggressive oxidizing gases [5-12]. Unfortunately, these coatings are relatively thick (generally $100 \mu \mathrm{m}-2 \mathrm{~mm}$ ), which makes it impossible to deposit them on wellmatched machine parts, because such thick coatings would become damaged during operation. In order to use TBC coatings in such situations, it is necessary to

Zbigniew Grzesik

grzesik@agh.edu.pl

1 Faculty of Materials Science and Technology, AGH University of Science and Technology, Al.

A. Mickiewicza 30, 30-059 Kraków, Poland 
redesign the elements so that they have smaller dimensions. However, this is an expensive process that requires modifying the production of the discussed elements and cannot be carried out with relative ease in every case. As a consequence, several working parts are completely unprotected from the effects of high-temperature corrosion. This can be seen, for example, in the case of engine valves used in lower and middle-class automobiles, even though exhaust engines work in extreme corrosive conditions due to the presence of aggressive exhaust gases and high temperatures up to $1173 \mathrm{~K}$. Thus, the development of a new generation of thin, inexpensive coatings, which ensure protection for moving parts against corrosion without the necessity of their redesign, is critically required. It has been determined that a good solution to this problem in the case of a nickel-chromium steel is to deposit pure chromium coatings around $1 \mu \mathrm{m}$ in thickness [13]. This research showed that such a thin chromium layer facilitates the growth of a scale consisting of chromiumrich oxides $\left(\mathrm{Cr}_{2} \mathrm{O}_{3}, \mathrm{CrMn}_{2} \mathrm{O}_{4}, \mathrm{Cr}_{1.5} \mathrm{Mn}_{1.5} \mathrm{O}_{4}\right)$ that demonstrate very good protective properties and enhance the heat resistance of the protected steel. The effect that the aforementioned coating has on the corrosion resistance of the steel can be explained as the thin chromium layer initiating the formation of the above-mentioned oxides, after which the coating quickly disappears and the scale continues to grow due to outward chromium diffusion from the metallic substrate. As a result, coated valve steels exhibit higher oxidation resistance under isothermal conditions compared to respective unmodified steels for a significantly longer time than the lifespan of the deposited coatings.

During the above-described studies, the following question was asked: Are thin chromium coatings the optimal solution from the point of view of protection against corrosion, or should the chromium layers be enriched with another element that positively affects heat resistance by means of synergy? When analyzing this aspect, it should be noted that greater nickel content in chromium-containing valve steels has a beneficial influence on improving their heat resistance $[14,15]$. Thus, we should determine whether an analogous phenomenon can be observed in the case of thin coatings containing both chromium and nickel. It should be noted that such an effect was reported in reference to the oxidation of the $\mathrm{Ni}-\mathrm{Cr}$ binary alloys [16]. However, in the case of the very thin coatings used in this work, this influence is not obvious due to relatively small Ni content and its possible inward diffusion into the steel.

The aim of this work was to study oxidation behavior under both isothermal and thermal shock conditions of four valve steels (X33CrNiMn23-8, X50CrMnNiNbN21-9, X53CrMnNiN20-8 and X55CrMnNiN20-8), currently utilized to manufacture engine valves, covered by $\mathrm{Cr}-\mathrm{Ni}$ thin coatings, and compared the obtained results to those determined for the respective steels covered by $\mathrm{Cr}$ coatings.

\section{Experimental Procedures}

In this work, four chromium-nickel engine valve steels (X33CrNiMn23-8, X50CrMnNiNbN21-9, X53CrMnNiN20-8 and X55CrMnNiN20-8), the measured chemical compositions of which are listed in Table 1, have been chosen for analysis. 
Table 1 Chemical composition of the analyzed valve steels (wt \%)

\begin{tabular}{llcllllllllll}
\hline Grade of steel & $\mathrm{C}$ & $\mathrm{Mn}$ & $\mathrm{Si}$ & $\mathrm{Cr}$ & $\mathrm{Ni}$ & $\mathrm{N}$ & $\mathrm{W}$ & $\mathrm{Nb}$ & $\mathrm{S}$ & $\mathrm{P}$ & $\mathrm{Mo}$ & $\mathrm{Fe}$ \\
\hline X33CrNiMn23-8 & 0.35 & 3.30 & 0.63 & 23.40 & 7.80 & 0.28 & 0.02 & - & $<0.005$ & 0.014 & 0.11 & bal. \\
X50CrMnNiNbN21-9 & 0.54 & 7.61 & 0.30 & 19.88 & 3.64 & 0.44 & 0.86 & 2.05 & 0.001 & 0.031 & - & bal. \\
X53CrMnNiN20-8 & 0.53 & 10.3 & 0.30 & 20.50 & 4.10 & 0.41 & - & - & $<0.005$ & 0.040 & 0.12 & bal. \\
X55CrMnNiN20-8 & 0.55 & 8.18 & 0.17 & 20.0 & 2.30 & 0.38 & - & - & $<0.005$ & 0.030 & 0.11 & bal. \\
\hline
\end{tabular}

The studied samples were $\sim$-mm-thick disks with $\sim 20 \mathrm{~mm}$ diameter that were obtained by cutting from rods of each steel. These disks were then prepared for oxidation studies by grinding the materials with $\mathrm{SiC}$ papers up to 1000 grit and subsequently polishing them using diamond pastes until a mirror finish was observed. The sequence of the aforementioned pastes used was 9,3 and then $1 \mu \mathrm{m}$. The prepared samples were then covered with $\sim 2$ - $\mu \mathrm{m}$-thick Cr-based layers containing 10 or $50 \%$ of nickel using the MS PVD (magnetron sputtering physical vapor deposition) method. The composition of the coatings, whenever mentioned in this work, refers to constituents content expressed in weight percent.

Two different targets were used in the magnetron sputtering processes, i.e., $\mathrm{Cr}-50 \mathrm{wt} \% \mathrm{Ni}$ and $\mathrm{Cr}-10 \mathrm{wt} \% \mathrm{Ni}$. Each of them exhibited purity on the level of $3 \mathrm{~N}$ (99.95 at.\%), as well as a 1 inch diameter and $2 \mathrm{~mm}$ thickness. As the deposition process was carried out, argon was dosed into the system in order to help the removal of atoms from the cathode surface and additionally ionize its stream. Argon concentration in the PVD chamber was precisely controlled by calibrated mass flow meters (maximum flow $500 \mathrm{sccm}$ ), as well as restricting valves.

The main processing parameters for the magnetron sputtering deposition were determined on the basis of previously performed deposition of pure $\mathrm{Cr}$ (purity $3 \mathrm{~N}$ ) directly on valve steels, as well as the physicochemical characteristics of $\mathrm{Cr}-\mathrm{Ni}$ alloy with 50 and $10 \mathrm{wt} \%$ of $\mathrm{Ni}$ content. The properties of nickel lead to faster sputtering on such targets compared to those that use pure Cr. Before carrying out the aforementioned processes to obtain coatings, the samples were purified with the help of acetone in an ultrasonic cleaner for $10 \mathrm{~min}$.

After the samples were placed in the reaction chamber, the system was evacuated to vacuum conditions the order of $1.0 \times 10^{-3} \mathrm{~Pa}$. Next, argon was entered into the system (200 sccm flow) and the pressure value was established in the chamber as 1.3 Pa. The optimal value of current intensity for sputtering $\mathrm{CrNi}$ targets was experimentally determined to be $0.1 \mathrm{~A}$. The duration of the $\mathrm{Cr}-50 \% \mathrm{Ni}$ and $\mathrm{Cr}-10 \% \mathrm{Ni}$ layer deposition processes was 30 and 60 min, respectively, for each of the sides of the modified valve steel samples. During the process, the magnetron was cooled by water flowing at a rate of $1.44 \mathrm{l} / \mathrm{min}$.

The samples, prepared according to the above-mentioned procedure, were then oxidized under both isothermal and thermal shock conditions. The temperature chosen in both cases was $1173 \mathrm{~K}$, which simulates the most extreme thermal condition inside modern automobile engines operating with self- or spark ignition. Mass change as a function of reaction time during oxidation under isothermal conditions 
was performed using the thermogravimetric method in a synthetic air atmosphere, i.e., with oxygen partial pressure equal to $2.1 \times 10^{4} \mathrm{~Pa}$. The mass gains of an investigated sample during the isothermal oxidation process were registered with a certain level of accuracy, the order of which was $10^{-6} \mathrm{~g}$. The duration of such experiments was $100 \mathrm{~h}$, which, from a practical point of view, means that it was more than a sufficient length of time, because automobile engines generally operate nonstop for much shorter periods.

Studies carried out under thermal shock conditions were realized by rapidly heating (for approximately $1 \mathrm{~min}$ ) each sample from room temperature (298 K) to $1173 \mathrm{~K}$, at which 2-h oxidation took place. Subsequently, the samples were rapidly cooled (quenched) for $2 \mathrm{~min}$ to room temperature, at which they remained

for $10 \mathrm{~min}$. Such a temperature change cycle was repeated several times in order to obtain information on the changes in sample mass as a function of the number of thermal shocks. Mass changes, in this case, take place due to overlapping mass growth processes resulting from the formation of oxidation products and simultaneous mass loss caused by scale spallation from the surface of the samples.

After oxidation tests, the phase morphology and composition of the reaction products (scales) were investigated by means of X-ray diffraction (XRD) and scanning electron microscopy (SEM) combined with energy dispersive X-ray analysis (EDX).

\section{Results and Discussion}

\section{Morphology and Adhesion of the Obtained Coatings to the Metallic Substrates}

In order to confirm that the chosen technological parameters were correct in the magnetron sputtering processes, microstructure and chemical composition studies were performed on the coated valve steels by using a Nova NANO SEM 200 (FEI, USA) scanning electron microscope equipped with an EDAX Genesis, USA energy dispersive X-ray analyzer. The observed microregions exhibited a uniform build, and the thickness of the deposited $\mathrm{Cr}$ layers was around $1.5 \mu \mathrm{m}$.

In order to determine the adhesion of the obtained $\mathrm{Cr}-\mathrm{Ni}$ coatings to the metallic substrates, the coefficient of friction was determined in each case, as well as the wear of the studied alloy surfaces (according to ASTM G 99-05, ISO 28808:20104) using a ball-shield tribology tester. The counter-specimen for these tests was a steel ball with a $6 \mathrm{~mm}$ diameter, velocity of $60 \mathrm{rot} / \mathrm{min}$ and $0.25 \mathrm{~N}$ load. As an example, Fig. 1 presents the results of the aforementioned tests obtained for both unmodified and covered X33CrNiMn23-8 steels. The coating on this steel undergoes delamination after around 240 and 280 cycles in the case of $\mathrm{Cr}-50 \% \mathrm{Ni}$ and $\mathrm{Cr}-10 \% \mathrm{Ni}$ coating, respectively.

In the case of the remaining steels, coating destruction takes place after a similar number of cycles. Additionally, surface wear studies were carried out to evaluate coating adherence to the substrate. The obtained values are listed in Table 2. On the basis of these results, it can be stated that coatings with greater Ni content exhibit greater wear 


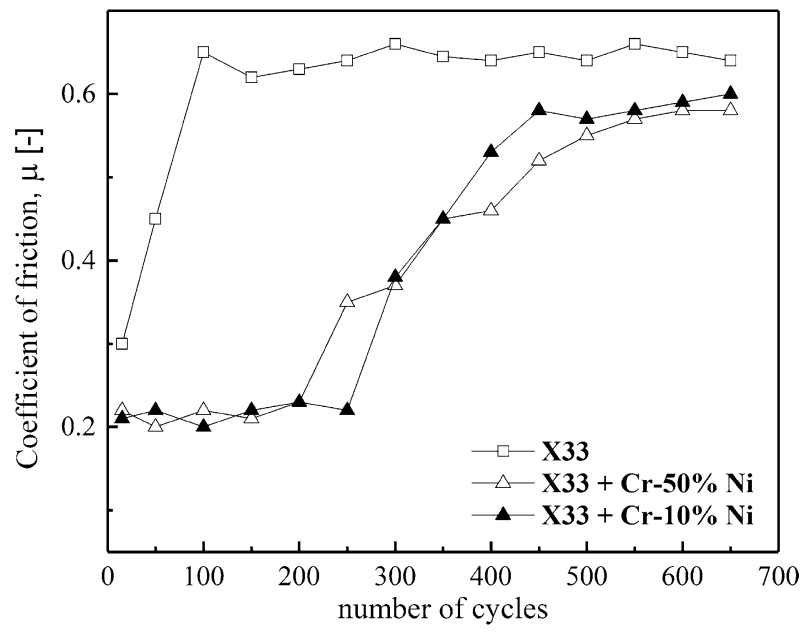

Fig. 1 Coefficient of friction $(\mu)$ values as a function of number of cycles for a selected unmodified steel, both unmodified and with protective CrNi coatings obtained by means of MS PVD

Table 2 Wear rate values obtained on valve steel surfaces with $\mathrm{Cr}-\mathrm{Ni}$ coatings

\begin{tabular}{ll}
\hline Material & Wear rate $\left(\mathrm{mm}^{3} / \mathrm{Nm}\right)$ \\
\hline $\mathrm{X} 33+\mathrm{Cr}-50 \% \mathrm{Ni}$ & $6.304 \times 10^{-4} \pm 2.875 \times 10^{-5}$ \\
$\mathrm{X} 33+\mathrm{Cr}-10 \% \mathrm{Ni}$ & $5.535 \times 10^{-4} \pm 3.163 \times 10^{-5}$ \\
$\mathrm{X} 50+\mathrm{Cr}-50 \% \mathrm{Ni}$ & $6.257 \times 10^{-4} \pm 3.165 \times 10^{-5}$ \\
$\mathrm{X} 50+\mathrm{Cr}-10 \% \mathrm{Ni}$ & $5.448 \times 10^{-4} \pm 3.387 \times 10^{-5}$ \\
$\mathrm{X} 53+\mathrm{Cr}-50 \% \mathrm{Ni}$ & $6.144 \times 10^{-4} \pm 2.144 \times 10^{-5}$ \\
$\mathrm{X} 53+\mathrm{Cr}-10 \% \mathrm{Ni}$ & $5.221 \times 10^{-4} \pm 2.984 \times 10^{-5}$ \\
$\mathrm{X} 55+\mathrm{Cr}-50 \% \mathrm{Ni}$ & $6.088 \times 10^{-4} \pm 2.018 \times 10^{-5}$ \\
$\mathrm{X} 55+\mathrm{Cr}-10 \% \mathrm{Ni}$ & $5.153 \times 10^{-4} \pm 3.690 \times 10^{-5}$ \\
\hline
\end{tabular}

(in the case of all studied steels). This is due to, among other things, the lower durability of Ni compared to the surface durability of $\mathrm{Cr}$.

When summarizing the studies on the quality of the deposited coatings, it should be emphasized that $\mathrm{Cr}-\mathrm{Ni}$ coatings (both $\mathrm{Cr}-50 \% \mathrm{Ni}$ and $\mathrm{Cr}-10 \% \mathrm{Ni}$ ) obtained on valve steels exhibit a good level of adhesion to all modified substrates. During the tests conducted, regions at which spallation of the protective layers took place were not observed. Furthermore, undesired effects during exposure of the modified steel surfaces to air on the adherence of the obtained coatings were not determined. It should be noted that the applied method of coating deposition also enables the performed processes to be repeatable. 


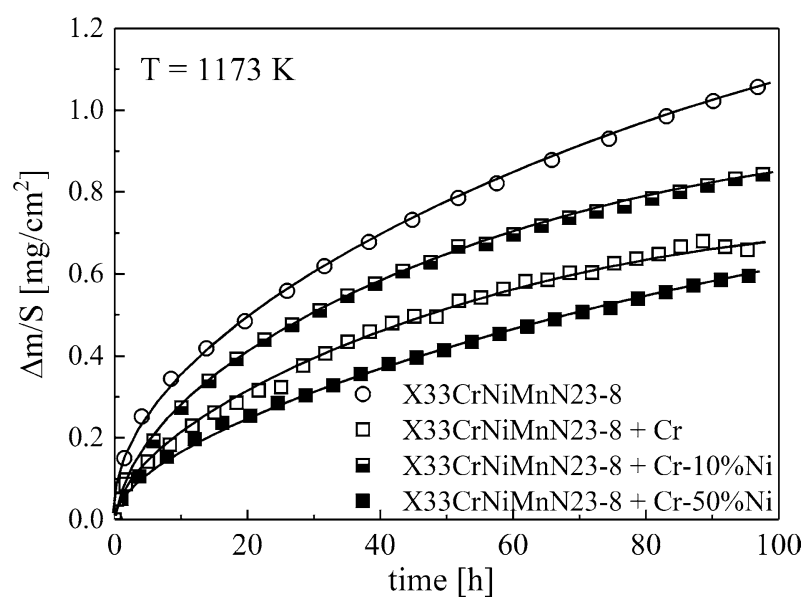

Fig. 2 Influence of the studied coatings on the oxidation kinetics of $\mathrm{X} 33 \mathrm{CrNiMn} 23-8$ steel under isothermal conditions

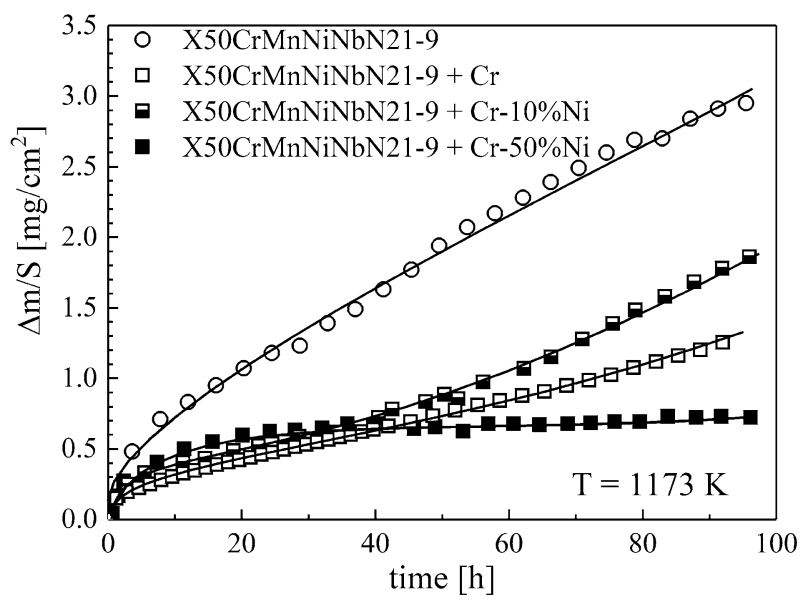

Fig. 3 Influence of the studied coatings on the oxidation kinetics of X50CrMnNiNbN21-9 steel under isothermal conditions

\section{Isothermal Oxidation Behavior of Valve Steels Covered by $\mathrm{Cr}-\mathrm{Ni}$ Coatings}

Figures 2, 3, 4 and 5 present the oxidation kinetics of the four discussed steels covered with $\mathrm{Cr}-50 \% \mathrm{Ni}$ and $\mathrm{Cr}-10 \% \mathrm{Ni}$ coatings. The plots indicate that application of chromium-nickel coatings leads to lower oxidation rates for the studied valve steels. Specific attention should be given to the very good heat-resistant properties of the $\mathrm{Cr}-50 \% \mathrm{Ni}$ coating. In the case of $\mathrm{X} 33 \mathrm{CrNiMn} 23-8$ steel, this coating exhibits better corrosion resistance than pure chromium throughout the entire duration of the test. For the remaining steels, this effect is observed only after a certain initial period of around $20-60 \mathrm{~h}$. The $\mathrm{Cr}-10 \% \mathrm{Ni}$ coating, on the other hand, ensures lower 


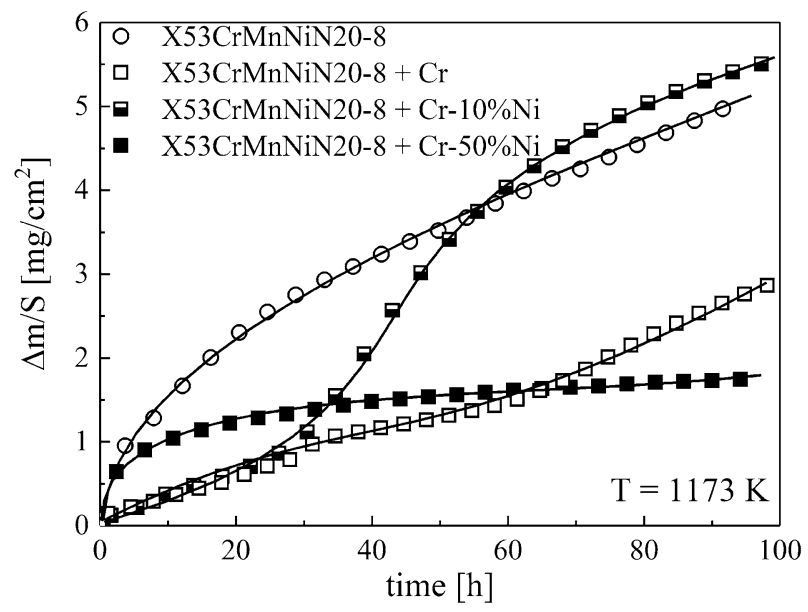

Fig. 4 Influence of the studied coatings on the oxidation kinetics of X53CrMnNiN20-8 steel under isothermal conditions

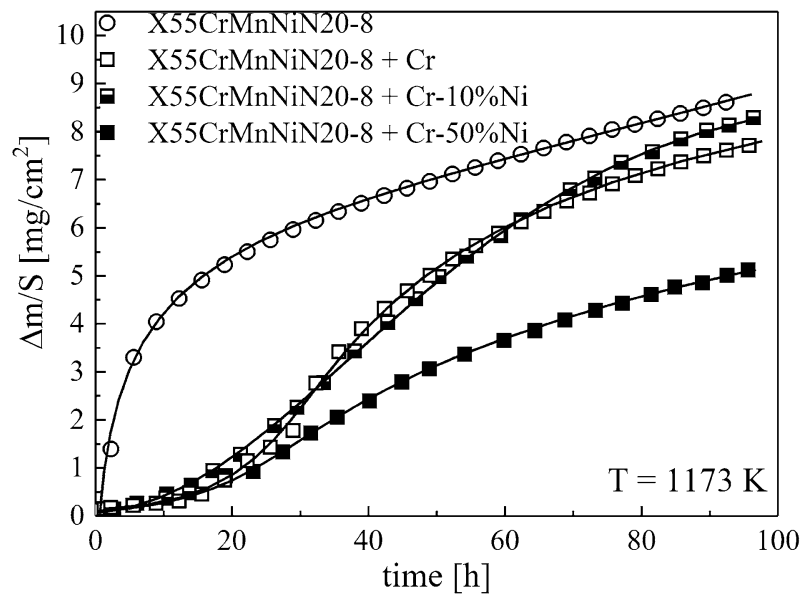

Fig. 5 Influence of the studied coatings on the oxidation kinetics of X55CrMnNiN20-8 steel under isothermal conditions

heat resistance compared to that guaranteed by a chromium layer. Furthermore, $\mathrm{X} 53 \mathrm{CrMnNiN} 20-8$ steel covered by that coating, after an initial oxidation period that lasts around $50 \mathrm{~h}$, undergoes faster oxidation than the same unmodified steel. This effect remains in a qualitative agreement with results obtained during oxidation of binary $\mathrm{Ni}-\mathrm{Cr}$ alloys [16]. It should be emphasized that, in the case of each steel, the positive effect of all the coatings is clearly visible and observed for a longer period of time than necessary for oxidizing a $1-\mu \mathrm{m}$ coating.

The increase in scaling resistance of steels after applying $\mathrm{Cr}-\mathrm{Ni}$ coatings is a result of the nature of the scale formed, in which the contribution of chromium 


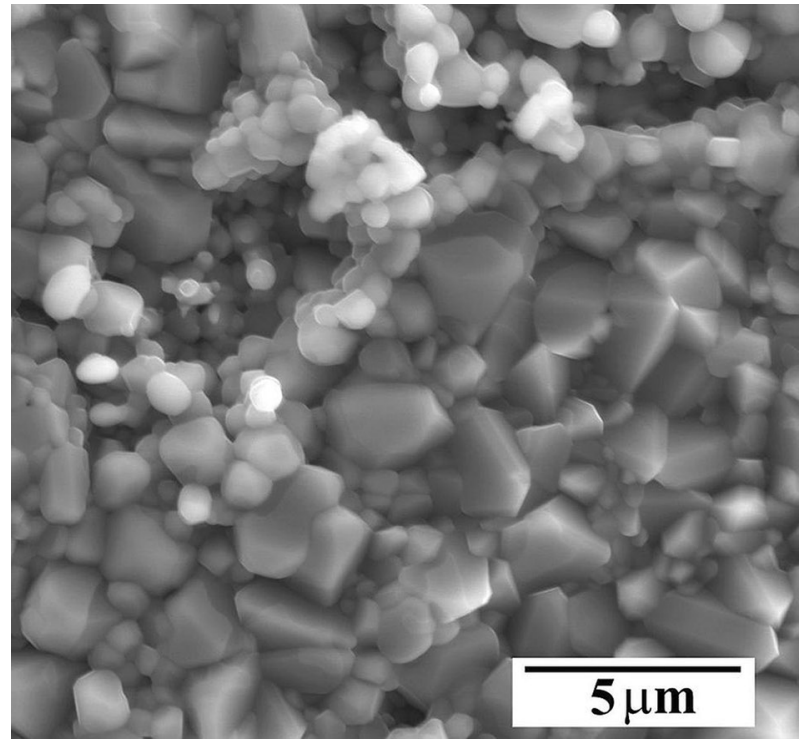

Fig. 6 Surface of the oxide scale grown on X33CrNiMn23-8 steel covered with a $\mathrm{Cr}-50 \% \mathrm{Ni}$ coating with visible small grains characteristic for $\mathrm{Cr}_{2} \mathrm{O}_{3}$

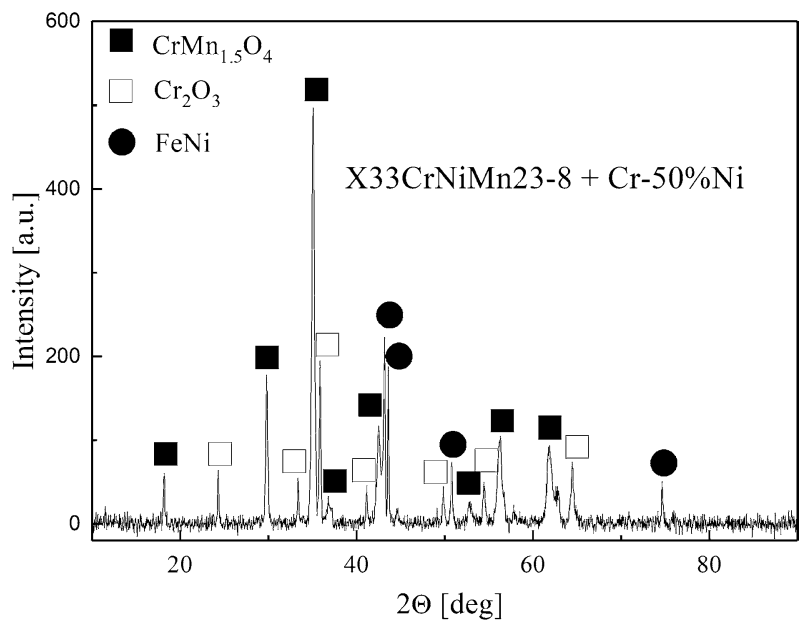

Fig. 7 XRD analysis of the oxide scale formed on X33CrNiMn23-8 steel covered with a Cr-50\%Ni coating

oxide and other oxide phases with very good heat-resistant properties is greater than that observed in the case of scales grown on uncoated steels. This fact is clearly confirmed by the SEM, EDX and XRD results obtained during oxidation of X33CrNiMn23-8 steel covered by a $\mathrm{Cr}-50 \% \mathrm{Ni}$ coating, presented in Figs. 6, 7 and Table 3, respectively. 
Table 3 EDX chemical composition analysis of the scale presented in Fig. 6

\begin{tabular}{lc}
\hline Element & $\begin{array}{l}\text { Atomic } \\
\text { percent } \\
(\%)\end{array}$ \\
\hline $\mathrm{O}$ & 39.32 \\
$\mathrm{Cr}$ & 8.96 \\
$\mathrm{Mn}$ & 24.70 \\
$\mathrm{Ni}$ & 27.02 \\
\hline
\end{tabular}

During oxidation of the uncovered remaining steels with lower chromium content (X50CrMnNiNbN21-9, X53CrMnNiN20-8 and X55CrMnNiN20-8), the outer layer of the scale is built of magnetite and hematite [16], which exhibit relatively poor protective properties. In contrast, the same steels covered by $\mathrm{Cr}-\mathrm{Ni}$ coatings form scales with chromium-containing oxides during oxidation. This situation is illustrated using X53CrMnNiN20-8 as an example in Fig. 8. Additionally, the morphology of the scale grown on $\mathrm{X} 53 \mathrm{CrMnNiN} 20-8$ during oxidation is presented in Fig. 9. The higher scaling resistance of these materials compared to unmodified steels is due to the presence of chromium oxide phases rich in chromium, manganese and nickel inside the scale, as indicated by the EDX results provided in Table 4.

\section{Oxidation Behavior of Valve Steels Covered by $\mathrm{Cr}$-Ni Coatings in Thermal Shock Conditions}

The results presented in Figs. 10, 11, 12 and 13 illustrating the oxidation rate in thermal shock conditions remain in complete qualitative agreement with microscopic

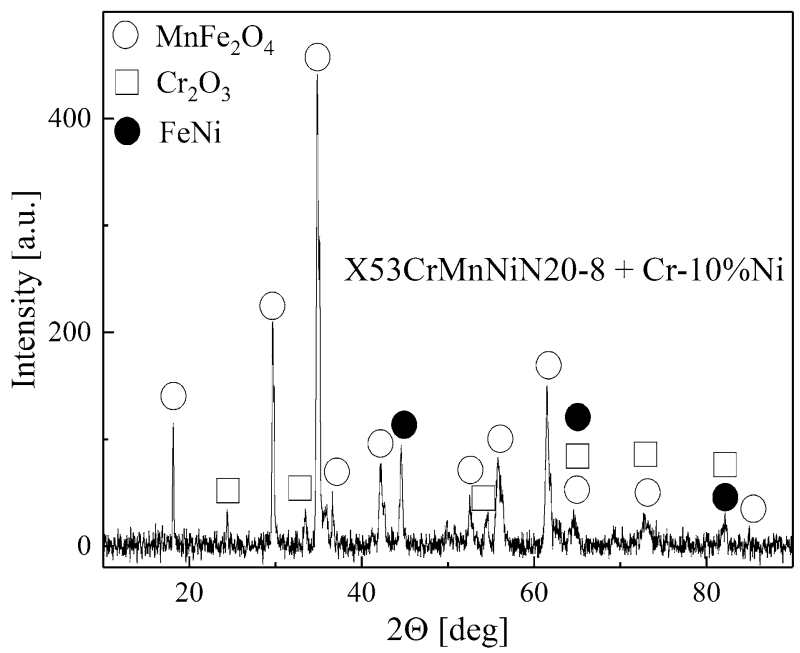

Fig. 8 XRD analysis of the oxide scale formed on X53CrMnNiN20-8 steel covered with a chromium coating containing $10 \%$ of $\mathrm{Ni}$ 


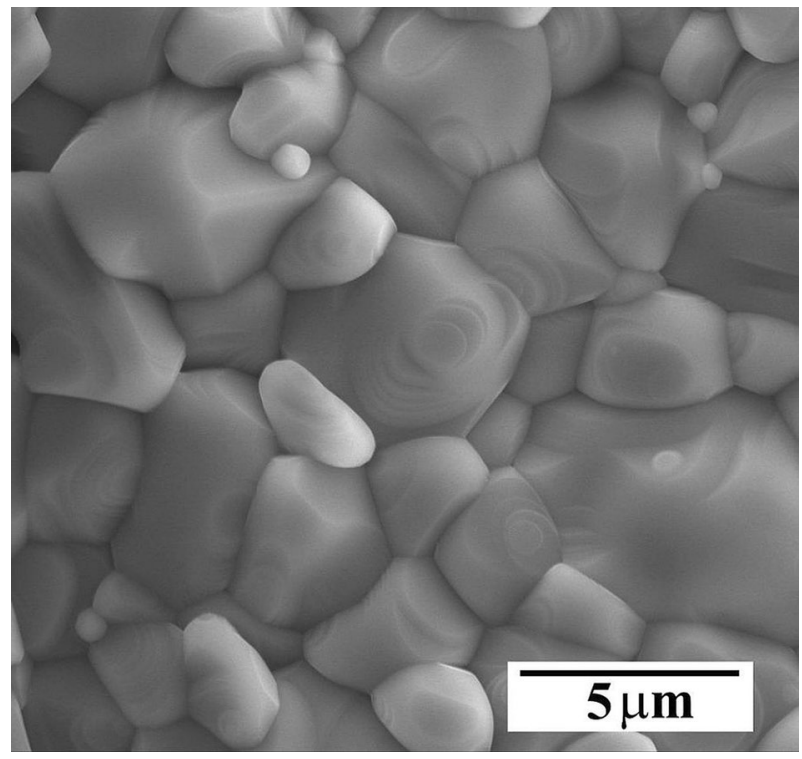

Fig. 9 Surface of the oxide scale formed on X53CrMnNiN20-8 steel covered with a $\mathrm{Cr}-10 \% \mathrm{Ni}$ coating

Table 4 EDX chemical composition analysis of the scale presented in Fig. 9

\begin{tabular}{lc}
\hline Element & $\begin{array}{l}\text { Atomic } \\
\text { percent } \\
(\%)\end{array}$ \\
\hline $\mathrm{O}$ & 42.04 \\
$\mathrm{Cr}$ & 19.85 \\
$\mathrm{Mn}$ & 26.76 \\
$\mathrm{Fe}$ & 9.96 \\
$\mathrm{Ni}$ & 1.39 \\
\hline
\end{tabular}

observations of the studied samples, shown in Figs. 14, 15, 16 and 17. The surface of the $\mathrm{X} 33 \mathrm{CrNiMn} 23-8$ steel (Fig. 14) shows the lowest signs of degradation, whereas the X53CrMnNiN20-8 (Fig. 16) and X55CrMnNiN20-8 (Fig. 17) steels underwent significant disintegration.

Analysis of the sample surface morphologies after cyclic oxidation suggests that iron oxides are practically absent in the scales of X33CrNiMn23-8 and X50CrMnNiNbN21-9 steels. As shown in Fig. 14, the scale grown on X33CrNiMn23-8 steel is built of small grains characteristic for chromium oxide. EDX analysis confirms the presence of mostly chromium in the scale, as well as some manganese (Table 5). Iron oxide, on the other hand, is practically not observed. The scale formed on $\mathrm{X} 50 \mathrm{CrMnNiNbN} 21-9$ steel covered with a $\mathrm{Cr}-50 \% \mathrm{Ni}$ coating consists of, aside from chromium oxide, oxide phases containing significant amounts of manganese. This is visible from the different grain sizes in the scale surface image presented in Fig. 15. In the case of X53CrMnNiN20-8 and X55CrMnNiN20-8 steels covered 


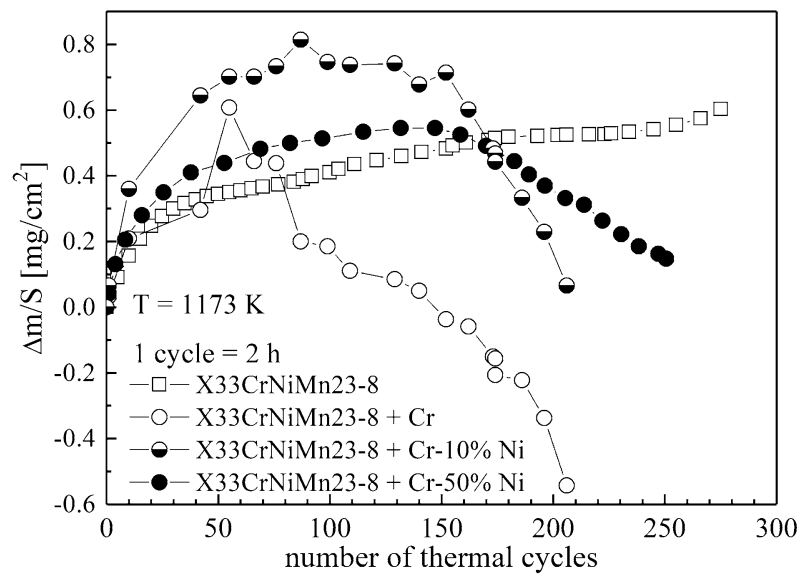

Fig. 10 Oxidation kinetics of $\mathrm{X} 33 \mathrm{CrNiMn} 23-8$ steel covered with $\mathrm{Cr}-50 \% \mathrm{Ni}$ coating in thermal shock conditions (298-1173 K), on the background of results obtained for the same steel with an unmodified surface and coated with a pure chromium layer

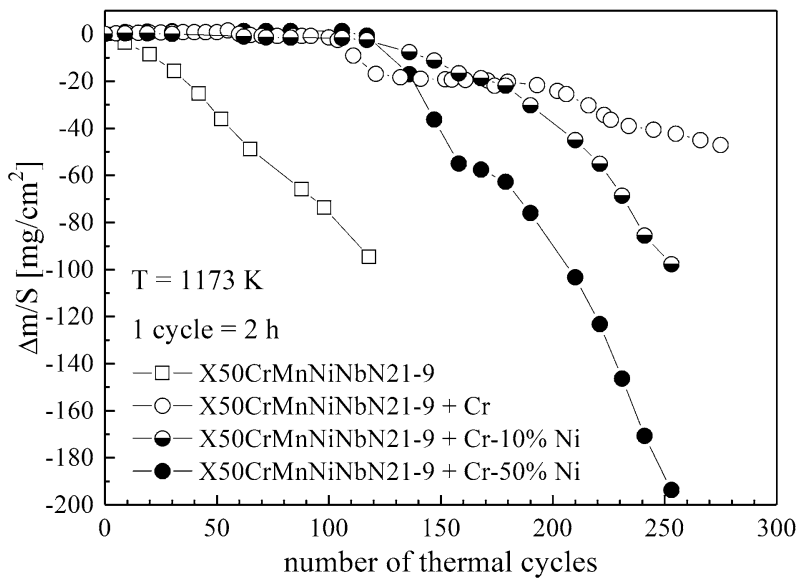

Fig. 11 Oxidation kinetics of $\mathrm{X} 50 \mathrm{CrMnNiNbN} 21-9$ steel covered with $\mathrm{Cr}-50 \% \mathrm{Ni}$ coating in thermal shock conditions (298-1173 K), on the background of results obtained for the same steel with an unmodified surface and coated with a pure chromium layer

with $\mathrm{Cr}-50 \% \mathrm{Ni}$, the scales consist of relatively large grains (Figs. 16, 17) and contain significant iron content (as suggested by the chemical composition presented for $\mathrm{X} 53 \mathrm{CrMnNiN20-8}$ in Table 6), the oxides of which exhibit poor protective properties.

The lower degradation level of valve steels covered with thin $\mathrm{Cr}-\mathrm{Ni}$ coatings compared to that observed for uncoated steels may be due to several reasons. First of all, coatings do not contain iron. This favors the formation of chromium-containing oxides on the surface of $\mathrm{Cr}-\mathrm{Ni}$ instead of iron oxides. 


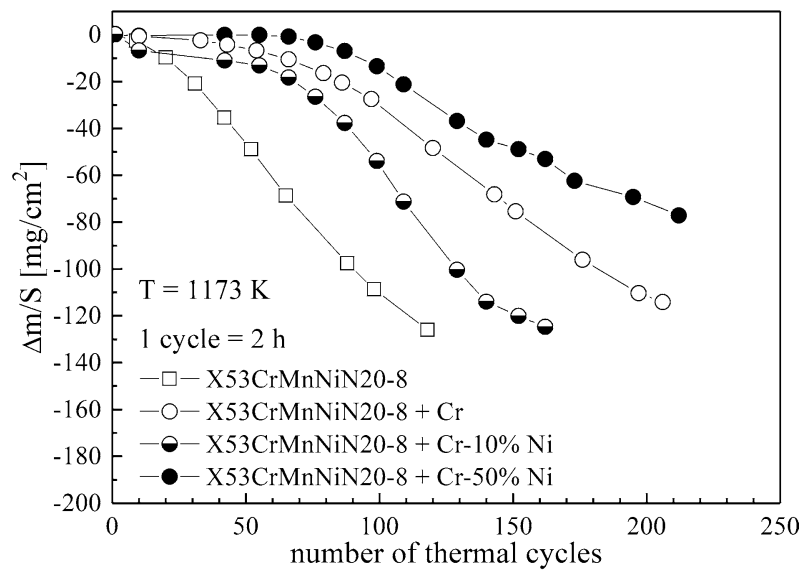

Fig. 12 Oxidation kinetics of $\mathrm{X} 53 \mathrm{CrMnNiN} 20-8$ steel covered with $\mathrm{Cr}-50 \% \mathrm{Ni}$ coating in thermal shock conditions (298-1173 K), on the background of results obtained for the same steel with an unmodified surface and coated with a pure chromium layer

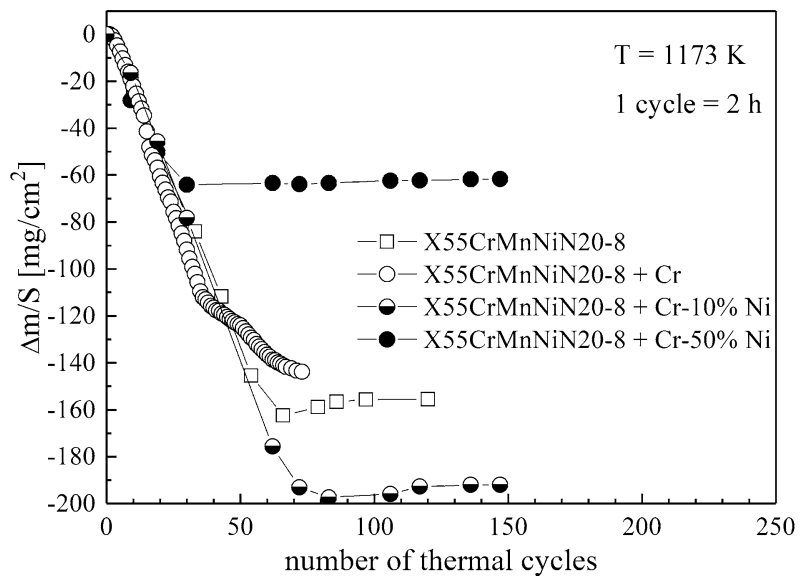

Fig. 13 Oxidation kinetics of $\mathrm{X} 55 \mathrm{CrMnNiN} 20-8$ steel covered with $\mathrm{Cr}-50 \% \mathrm{Ni}$ coating in thermal shock conditions (298-1173 K), on the background of results obtained for the same steel with an unmodified surface and coated with a pure chromium layer

As chromium-rich oxides exhibit better protective properties than iron oxides, the grown scales are thinner, and thus the destructive mechanical stresses, present during thermal shocks in metallic core/scale system, are lower. It should be also noted that the difference between thermal expansion coefficients for studied steels and $\mathrm{Cr}-\mathrm{Ni}$ coatings is lower than in the case of the system consisting of valve steels coated with $\mathrm{Cr}$ (X33CrNiMn23-8: $\alpha=17.4 \times 10^{-6} \mathrm{~K}^{-1}$ [17]; X50CrMnNiNbN21-9, X53CrMnNiN20-8, X55CrMnNiN20-8: $\alpha=18.8 \times 10^{-6} \mathrm{~K}^{-1}$ [17]; Ni-Cr: $\alpha=17.3 \times 10^{-6} \mathrm{~K}^{-1}$ [18]; Cr: $4.9 \times 10^{-6} \mathrm{~K}^{-1}$ 


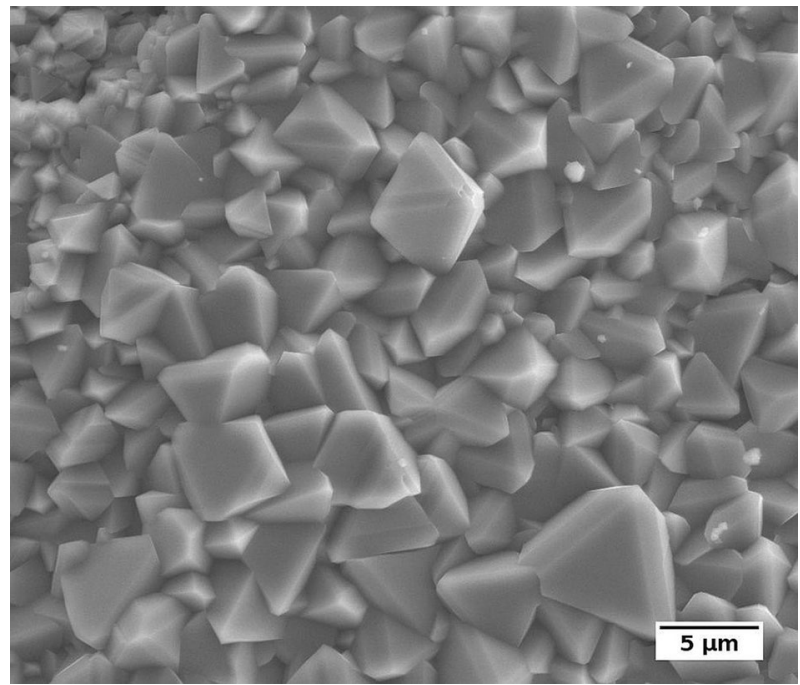

Fig. 14 Surface of the oxide scale grown on $\mathrm{X} 33 \mathrm{CrNiMn} 23-8$ steel covered with a $\mathrm{Cr}-50 \% \mathrm{Ni}$ coating with visible small grains characteristic for $\mathrm{Cr}_{2} \mathrm{O}_{3}$

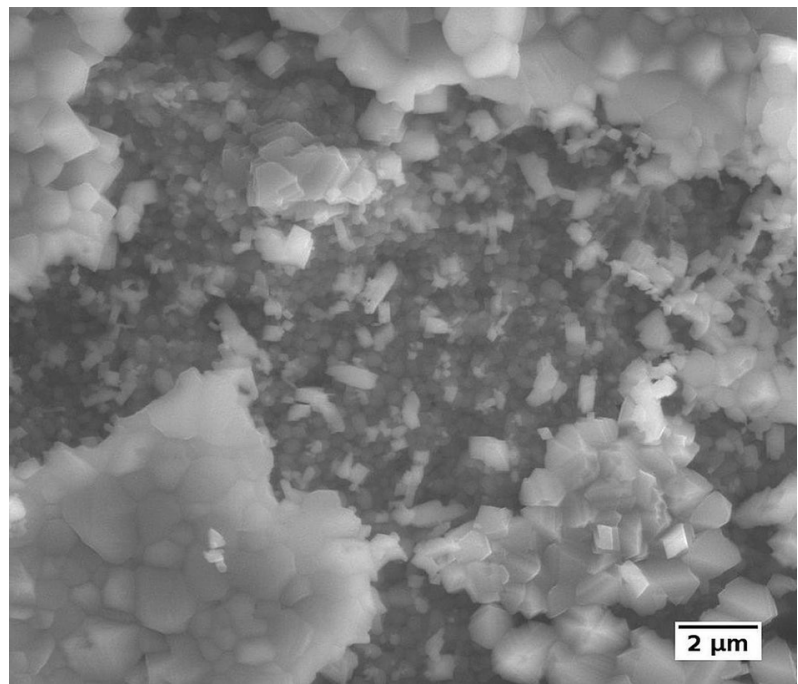

Fig. 15 Oxide scale surface on $\mathrm{X} 50 \mathrm{CrMnNiNbN21-9}$ steel covered with a $\mathrm{Cr}-50 \% \mathrm{Ni}$ coating

[19]). More similar values of such coefficients ensure better adhesion between the coating and the steel, thereby reducing the spallation process and decreasing the degradation rate of investigated materials. 


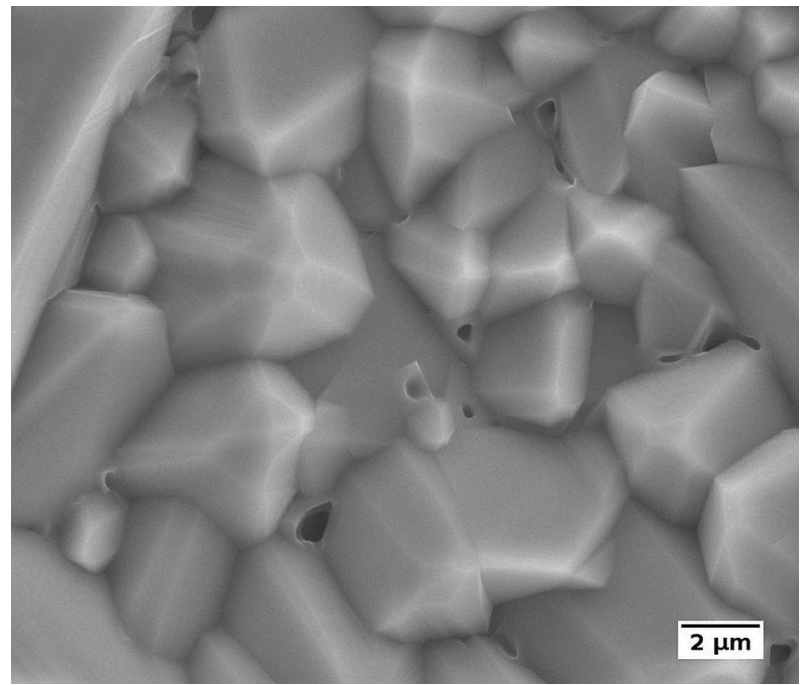

Fig. 16 Oxide scale surface on $\mathrm{X} 53 \mathrm{CrMnNiN} 20-8$ steel covered with a $\mathrm{Cr}-50 \% \mathrm{Ni}$ coating

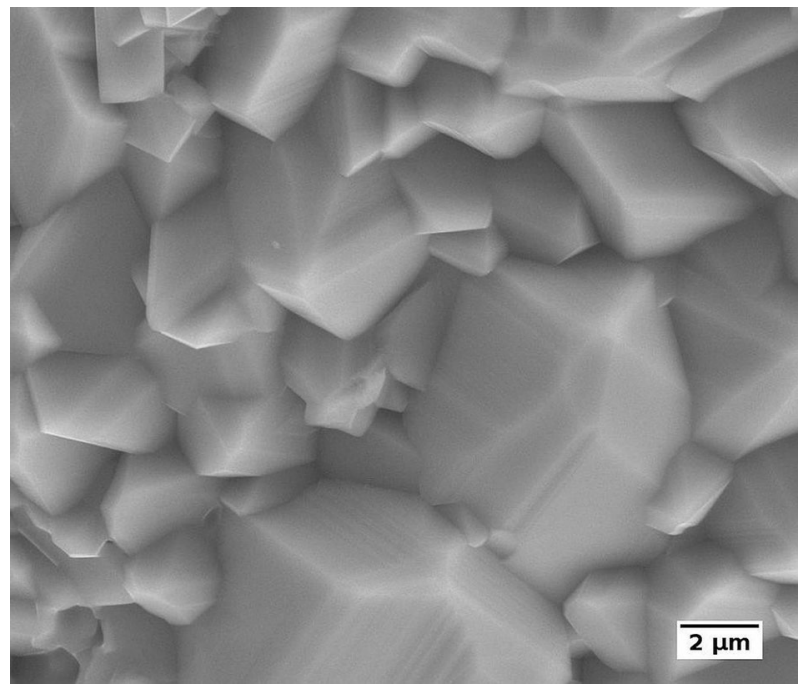

Fig. 17 Oxide scale surface on $\mathrm{X} 55 \mathrm{CrMnNiN} 20-8$ steel covered with a $\mathrm{Cr}-50 \% \mathrm{Ni}$ coating

\section{Conclusions}

Application of $\mathrm{Cr}-\mathrm{Ni}$ coatings with $1 \mu \mathrm{m}$ thickness effectively increases heat resistance of investigated valve steels under both isothermal and thermal shock conditions. This phenomenon can be attributed to the formation of chromium-rich oxides (e.g., $\mathrm{Cr}_{2} \mathrm{O}_{3}, \mathrm{NiCr}_{2} \mathrm{O}_{4}, \mathrm{MnCr}_{2} \mathrm{O}_{4}$ ) during oxidation, which exhibit better protective 
Table 5 EDX analysis of the chemical composition of the scale grown on X33CrNiMn23-8 steel covered with a $\mathrm{Cr}-50 \% \mathrm{Ni}$ coating

Table 6 EDX analysis of the chemical composition of the scale grown on X53CrMnNiN20-8 steel covered with a $\mathrm{Cr}-50 \% \mathrm{Ni}$ coating

\begin{tabular}{ll}
\hline Element & $\begin{array}{l}\text { Atomic } \\
\text { percent } \\
(\%)\end{array}$ \\
\hline $\mathrm{O}$ & 46.11 \\
$\mathrm{Cr}$ & 26.78 \\
$\mathrm{Mn}$ & 18.93 \\
$\mathrm{Fe}$ & 1.95 \\
$\mathrm{Ni}$ & 6.23 \\
\hline
\end{tabular}

\begin{tabular}{lc}
\hline Element & $\begin{array}{l}\text { Atomic } \\
\text { percent } \\
(\%)\end{array}$ \\
\hline $\mathrm{O}$ & 41.73 \\
$\mathrm{Cr}$ & 3.01 \\
$\mathrm{Mn}$ & 23.33 \\
$\mathrm{Fe}$ & 28.68 \\
$\mathrm{Ni}$ & 3.25
\end{tabular}

properties than iron oxides $\left(\mathrm{Fe}_{3} \mathrm{O}_{4}\right.$ and $\left.\mathrm{Fe}_{2} \mathrm{O}_{3}\right)$ grown on unmodified steels under analogous conditions. The positive effect of thin $\mathrm{Cr}-\mathrm{Ni}$ coatings is observed for a much longer time than the lifetime of the coatings. Consequently, the obtained results indicate the previously unnoticed potential of thin metallic coatings, enabling their application as a means of protection against high-temperature corrosion in several branches of modern industry.

Acknowledgements This work was supported by The National Science Centre, Poland, within the framework no. 2014/13/B/ST8/04312.

Open Access This article is distributed under the terms of the Creative Commons Attribution 4.0 International License (http://creativecommons.org/licenses/by/4.0/), which permits unrestricted use, distribution, and reproduction in any medium, provided you give appropriate credit to the original author(s) and the source, provide a link to the Creative Commons license, and indicate if changes were made.

\section{References}

1. B. Gleeson, in Materials Science and Technology, eds. R. W. Cahn, P. Haasen and E. J. Kramer (Wiley-VCH, Weinheim, 2000), p. 174.

2. H. E. Evans, in Shreir's Corrosion, 4th ed, ed. R. A. Cottis (Elsevier Ltd, Amsterdam, 2010), p. 691.

3. S. Chevalier, in Developments in High-Temperature Corrosion and Protection of Materials, ed. W. Gao (Woodhead Publishing in Materials, Cambridge, 2008), p. 290.

4. E. N'Dah, S. Tsipas, M. P. Hierro and F. J. Perez, Corrosion Science 49, 3850 (2007).

5. H. Xu, H. Guo and S. Gong, in Developments in High-Temperature Corrosion and Protection of Materials, ed. W. Gao (Woodhead Publishing in Materials, Cambridge, 2008), p. 476.

6. G. Selim, S. F. Diltemiz and M. C. Kushan, Oxidation of Metals 31, 149 (2017).

7. J. Wells, N. Chapman, J. Sumner and P. Walker, Oxidation of Metals 88, 97 (2017). 
8. R. Vassen, M. O. Jarligo, T. Steinke, D. E. Mack and D. Stöver, Surface and Coatings Technology 205, 938 (2010).

9. H. B. Guo, R. Vaßen and D. Stöver, Surface and Coatings Technology 192, 48 (2005).

10. D. Stöver, G. Pracht, H. Lehmann, M. Dietrich, J.-E. Döring and R. Vaßen, Journal of Thermal Spray Technology 13, 76 (2004).

11. M. Shen, P. Zhao, Y. Gu, S. Zhu and F. Wang, Corrosion Science 94, 294 (2015).

12. Y. Chen, X. Zhao, M. Bai, L. Yang, C. Li, L. Wang, J. A. Carr and P. Xiao, Acta Materialia 128, 31 (2017).

13. M. Drożdż, K. Kyzioł and Z. Grzesik, Materials Technology 51, 603 (2017).

14. Z. Grzesik, G. Smola, K. Adamaszek, Z. Jurasz and S. Mrowec, Corrosion Science 77, 369 (2013).

15. Z. Grzesik, G. Smola, K. Adamaszek, Z. Jurasz and S. Mrowec, Oxidation of Metals 80, 147 (2013).

16. G. C. Wood, I. G. Wright, T. Hodgkiess and D. P. Whittle, Werkst Korros 1, 900 (1970).

17. Steel and cast iron standards PN-EN 10090: 1998 Valve steels and alloys for internal combustion engines.

18. http://www.repairengineering.com/coefficient-of-thermal-expansion.html\#top. Accessed January $10,2019$.

19. D. R. Lide, CRC Handbook of Chemistry and Physics, (CRC Press, Boca Raton, 2005).

Publisher's Note Springer Nature remains neutral with regard to jurisdictional claims in published maps and institutional affiliations. 